\title{
Per-unit versus ad-valorem royalty licensing in a Stackelberg market
}

\author{
Manel Antelo ${ }^{1}$ iD $\cdot$ Lluís Bru ${ }^{2}$
}

Received: 7 May 2021 / Revised: 25 September 2021 / Accepted: 4 December 2021 /

Published online: 18 December 2021

(C) The Author(s) 2021

\begin{abstract}
We consider licensing of a non-drastic innovation by a licensor that interacts with a potential licensee in a Stackelberg duopoly, comparing per-unit and ad-valorem royalty two-part contracts and showing why and when each licensing deal should be used. We contribute three findings to the literature. First, ad-valorem royalty is preferred when the licensor plays as leader in the marketplace, but per-unit royalty is preferred when the licensor plays as follower. Second, only innovations that do not hurt consumers are socially beneficial. Third, our model also suggests that both the licensor's status as a leader or follower in the marketplace and the innovation size determine the incentive to engage in innovative activities.
\end{abstract}

Keywords Licensing $\cdot$ Per-unit royalties · Ad-valorem royalties · Leader · Follower · Welfare

JEL Classification L13 - L24

\section{Introduction}

Empirical evidence on licensing deals indicates that innovators often transfer their patented innovations to direct competitors (Jiang \& Shi, 2018) and that most licensing contracts feature positive royalties (Bousquet et al., 1998; Lim \& Veugelers, 2003). ${ }^{1}$ In this paper we discuss two additional aspects relevant for licensing

\footnotetext{
1 A patent licensing survey performed in 2007 by the OECD found that $20 \%$ and $29 \%$ of respondent firms in Europe and Japan, respectively, out-licensed patents to non-affiliated partners (Zuniga and Guellec, 2009). Another similar survey conducted by the European Commission (Radauer and Dudenbos-

Manel Antelo

manel.antelo@usc.es

Lluís Bru

lluis.bru@uib.es

1 Universidade de Santiago de Compostela, Santiago de Compostela, Spain

2 Universitat de les Illes Balears, Palma de Mallorca, Spain
} 
arrangements. First, that often one of the firms in the industry has accumulated an advantage over time, which is reflected in its current market dominance. This competitive advantage may derive from prior technological superiority leading to a large customer base, well-known trademarks, etc.; and in the case of incumbents against start-ups, also from the fact that new firms face constraints in their production capacity, must build their own supply chain and distribution network, etc. In our analysis below, we will represent this incumbency feature through a Stackelberg game, where the more established firm will be the first-mover player in the marketplace.

The second important aspect to consider is that, at a given time, any of the two firms can have the technological leadership. Hence the holder of a new technology can be either the leader in setting the output level (the most established firm) or the follower (the entrant) of the industry. There are many firms playing as leaders in their product markets and that frequently license their patented innovations to competitors. Jiang and Shi (2018) discuss the examples of Procter and Gamble and Ford. At the same time, the case of AMD in the semiconductor industry features an example of a licensor that plays as follower in the marketplace. AMD microprocessors for PCs compete with those from Intel, ${ }^{2}$ and until recently Intel almost monopolized this market, but currently AMD has the technological leadership; as a consequence, while in 2015 Intel's share for desktop and laptop microprocessors was at $92.4 \%$, in 2021 AMD's share was over $17 \% .^{3}$ Notice that AMD technological advantage does not mean that it has overtaken Intel in terms of market share. Moreover, this rivalry does not exclude that AMD and Intel extensively cross-license each other's technologies, so that both firms end up offering products of similar quality.

The empirical literature does not provide clear-cut results on the relationship between firm size and innovation, and although the tendency seems to be positive, it is not necessarily linear. Therefore, it can be assumed that both a leading firm and a follower firm in setting the quantity to produce, and thus having a different size, can become the licensor of a new technology. For example, according to Acs and Audretsch (1987, 1990), the relationship between firms' size and innovation depends on industry characteristics, so that in highly concentrated sectors with high entry barriers, large firms tend to innovate (and become licensors) more than small firms, whereas the opposite holds for less concentrated sectors reflecting emerging or growing technologies. As for the relationship between innovation and firm age (another proxy for incumbency), the evidence indicates that challengers invest more in R\&D than more established firms when the goal is to enter new markets (Reinganum, 1983; Czarnitzki \& Kraft, 2004); this suggests that older firms may be less R\&D-intensive than their younger counterparts. Finally, Huergo and Jaumandreu

\footnotetext{
Footnote 1 (continued)

tel, 2013) reported that $56 \%$ of European patent-holding firms were engaged in out-licensing activities, while another $16 \%$ planned to consider this option for the future. As an example of the importance of licensing as a crucial revenue source for firms, Nokia's reported brand and technology licensing net sales amounted to 1.6 billion euros in 2017 (Nokia Corporation Financial Report, 2018).

2 AMD is also the lesser firm for graphic processors units (GPU), up against those from Nvidia.

3 See “AMD's Share of $\times 86$ CPU Market Hits 14-Year High", PCmag, August 12, 2021, available at https://www.pcmag.com/news/amds-share-of-x86-cpu-market-hits-14-year-high
} 
(2004) find that the probability of innovating varies widely by activity, that small size per se broadly reduces the probability of innovation and that entrant firms are more likely to innovate than older firms. Summing up, both the firm that plays as leader or follower in the product market can be the one that innovates and licenses the resulting technology.

Since the main motivation of innovative firms for licensing out their patents is to earn revenue, they will try to devise a licensing arrangement that ensures the maximum payoff. The empirical literature shows that contingent royalties-either per-unit royalty (non-negative uniform royalty per unit of production) or ad-valorem royalty (non-negative royalty based on a percentage of licensee sales) - are commonly included in licensing contracts (e.g., Bousquet et al., 1998; Lim \& Veugelers, 2003; Trombini \& Comacchio, 2012). In this respect, our work examines how the position of a firm in a market, namely its role as a leader or a follower in the Stackelberg game, affects the type of royalty chosen (per-unit or ad-valorem) when licensing a process technology.

The theoretical literature shows that the rationale for using contingent royalties in licensing deals lies in factors such as demand or cost uncertainty (Bousquet et al., 1998), product differentiation, a licensee's new product development cost (San Martín and Saracho, 2016), or the relative efficiency of the licensee compared to the licensor (Fan et al., 2018a). Two papers have analysed the choice between per-unit and ad-valorem royalties in a Cournot setting: San Martín and Saracho (2010) find that, under full information, an ad-valorem royalty is the preferred licensing contract. This is because ad-valorem royalty compared to per-unit royalty allows the licensor to relax market competition. Fan et al. (2018a) show that per-unit licensing is more profitable if the licensor is more efficient than the licensee in using the innovation, whereas ad-valorem licensing is more profitable in the reverse scenario.

In this paper we describe the interaction between firms in a duopoly using the Stackelberg leadership model, ${ }^{4}$ that we believe better reflects the characteristics we have described above rather than a Cournot duopoly, and we contribute three findings to the literature. First, the kind of royalty offered crucially depends on the licensor's status as a leader or follower in the product market. In particular, the superiority of ad-valorem over per-unit royalty in a Cournot setting no longer holds when the licensor is the follower in the Stackelberg game. In this set-up, per-unit royalty is more collusive than ad-valorem royalty and allows the licensor to reap more license revenues.

Our second finding is related to the licensing impact on social welfare. While, in a Cournot setting, licensing as compared to no licensing unequivocally hurts both consumers and society (San Martín \& Saracho, 2010), in a Stackelberg environment the licensing impact on consumers and society as a whole depends on the licensor's status in the marketplace. The diffusion of an innovation harms consumers and society only when the licensor is the market leader; if the licensor plays as a follower,

\footnotetext{
${ }^{4}$ Filippini (2005) examined licensing in a Stackelberg model, but restricted the analysis to a licensor that acts as a leader in the output market and uses per-unit royalty as the licensing scheme.
} 
the consumer surplus remains unaltered and society as a whole is better off in welfare terms after licensing because there is an increase in production efficiency. ${ }^{5}$

Finally, we also show that the incentive to undertake innovative activities and license an innovation largely depends on both the licensor's status in the product market and the size of the innovation: when the size of the innovation is sufficiently small, the incentive to innovate and disseminate the resulting innovation is higher for a leader licensor than for a follower licensor, while the opposite holds for a large innovation. In this respect, our paper complements Wang and Yang (2004)'s research. These authors find that in a linear Stackelberg duopoly like ours, the follower innovator is more likely to license a cost-reducing innovation to the leader than the leader innovator is to the follower, regardless of whether licensing is in the form of a fixed fee or royalty per unit of output. Under fixed-fee licensing, the follower gains more from small innovations while the leader gains more from large non-drastic innovations. Under royalty licensing, however, it is the follower in the product market who always gains more than the leader from an innovation.

The rest of the paper is structured as follows. Section 2 outlines the model and Sect. 3 examines the preferred method-ad-valorem two-part or per-unit two-part contracting - for a licensor to license the innovation. Section 4 analyses the welfare impact of licensing, Sect. 5 studies the effect of the licensor's status in the product market on the incentive to innovate, and finally, Sect. 6 concludes.

\section{The model}

Consider a Stackelberg duopoly industry with firms 1 and 2 producing an undifferentiated good. Consumers in this market exhibit the following linear piecewise demand function:

$$
p(Q)=\max \{0, a-Q\} \quad \text { with } Q=q_{1}+q_{2}
$$

where $q_{i}$ denotes the quantity produced by firm $i(i=1,2)$ and parameter $a>0$ represents the market size. Firms produce the good with their existing technology, which leads them to borne the constant marginal cost $c>0$. There are no fixed costs of production. In this context, one of the firms in the industry, either the leader or the follower in setting the output level, owns an R\&D division that develops an innovation which reduces the marginal cost from $c$ to 0 .

Throughout this paper we make the following assumption concerning the cost reduction induced by the innovation:

Assumption 1 The size of the innovation, $c$, is such that $0<c<a / 3$.

\footnotetext{
5 Kabiraj (2005), in studying optimal licensing contracts in a leadership structure along with the welfare implications, shows that aggregate welfare depends on the types of contracts available and on ownership of the patent. In particular, there are situations when a follower's innovation generates larger welfare than a leader's innovation.
} 
This assumption ensures that all firms are previously active even if licensing does not take place or, alternatively, that the innovation is non-drastic irrespective of whether the owner behaves as leader or follower in the product market. A consequence of Assumption 1 is that non-licensing the innovation does not give rise to a monopoly.

The innovative firm can license its innovation to the rival by means of a two-part contract $^{6}$ that includes either a non-negative uniform royalty per unit of production (per-unit royalty), or a non-negative royalty based on a percentage of sales (ad-valorem royalty), plus possibly a fee. ${ }^{7}$ The marginal cost of selling the licence is zero. The licensor is assumed to have all the bargaining power, and the licensee therefore always obtains its outside option (i.e. its profit absent licensing). The potential licensee acquires the innovation if its profit after payments is larger than that obtained without the licence, in which case it is operating at marginal cost $c$ against the innovative firm with zero marginal cost.

The analysis follows a four-stage non-cooperative game. In the first stage, the innovator, either the market leader or the market follower in setting the output level, decides whether to license the innovation to its rival and, in the case of licensing, offers either a per-unit two-part contract or an ad-valorem two-part contract. In the second stage, the potential licensee, either the follower or leader in setting the output level, accepts or refuses the licensor's offer. If the offer is accepted, then, in the third stage, the leader-the licensor or the licensee, as the case may be-chooses its level of production. Finally, in the fourth stage, the follower-the licensee or the licensor, as the case may be-observes the output level of the leader-the licensor or the licensee, as the case may be-and decides its own quantity. As usual, we look for a Subgame Perfect Nash equilibrium for this licensing game.

\section{The licensor's decision}

\subsection{The licensor plays as leader in setting the output level}

In this section we consider the leader firm in the marketplace to be the licensor. In this case, if the licensing contract takes the form of per-unit two-part tariff, i.e. a fixed-fee payment $f$ plus a royalty rate per unit sold $r, r \leq c,{ }^{8}$ and the licensee accepts the licensor's offer, then, in the fourth stage of the game, once the leader/ licensor chooses to produce $q_{L}$, where subscript $L$ indicates leadership status, the

\footnotetext{
${ }^{6}$ It is common to see two-part tariff licensing contracts in the literature and reality. For example, Fan et al. (2018b) show that, under incomplete information, an inside licensor generally increases its payoff by using per-unit two-part tariffs rather than pure per-unit royalty contracts.

${ }^{7}$ Licensing by means of a pure fixed-fee payment is obviated, because such an arrangement is never optimal for the licensor, irrespective of whether it plays as the leader or the follower in the product market.

8 The follower/licensee could accept a per-unit royalty rate $r>c$ if this led to a sufficiently high price through more collusive behaviour on the part of the leader/licensor. Of course, firms could not offer an efficiency rationale for such a royalty rate (the follower would produce under higher marginal costs of production) and a competition authority would ban such a rate.
} 
follower/licensee must choose the quantity $q_{F}$ (subscript $F$ denotes followership status) that maximizes its profit, i.e.:

$$
q_{F}=\operatorname{argmax}_{q} \pi_{F}^{u}=\left(a-r-q_{L}-q\right) q
$$

where superscript $u$ denotes per-unit royalty. Solving the problem defined in (2) affords $q_{F}\left(q_{L}\right)=\left(a-r-q_{L}\right) / 2$. The licensor's optimal quantity is then given by:

$$
q_{L}=\operatorname{argmax}_{q} \pi_{L}^{u}=(a-q-(a-r-q) / 2) q+r(a-r-q) / 2
$$

which yields $q_{L}=a / 2$. Thus, the licensee produces $q_{F}=(a-2 r) / 4$ and obtains profit $\pi_{F}^{u}(r)=\left(\frac{a-2 r}{4}\right)^{2}$.

In the second stage of the game, the follower accepts the licence contract whenever this profit is larger than that which would be achieved using the old technology, in which case the leader would produce $q_{L}^{n}=(a+c) / 2$, and the follower would produce the strictly positive quantity ${ }^{n} q_{F}^{n}(a-3 c) / 4$, where superscript $n$ stands for no licence. As result, the follower/licensee's profit amounts to $\pi_{F}^{n}=\left(\frac{a-3 c}{4}\right)^{2}$ and the leader/licensor chooses the two-part tariff contract $(f, r)$ that solves:

$$
\begin{aligned}
\max _{(f, r)} \pi_{L}^{u} & =\left(f+r \frac{a-2 r}{4}\right)+\frac{a(a+2 r)}{8} \\
\text { s.t } & :\left\{\begin{array}{c}
\pi_{F}^{u}(r)-f \geq \pi_{F}^{n} \\
r \leq c
\end{array}\right\}
\end{aligned}
$$

The follower/licensee's participation constraint in (4) leads to $f=\pi_{F}^{u}(r)-\pi_{F}^{n}=\left(\frac{a-2 r}{4}\right)^{2}-\left(\frac{a-3 c}{4}\right)^{2}$. Note that $r \leq c$ implies that $\pi_{F}^{u}(r)>\pi_{F}^{n}$ and, consequently, the leader/licensor can charge a positive fee, $f>0$. Thus, the problem stated in (4) can be written as:

$$
\max _{r}\left(\frac{a-2 r}{4}\right)^{2}-\left(\frac{a-3 c}{4}\right)^{2}+r \frac{a-2 r}{4}+\frac{a(a+2 r)}{8}, \quad \text { s.t }: r \leq c
$$

While a (linear) per-unit contract would limit the rent extraction of the licensor and would force it to leave some rents to the licensee, the fixed payment in the perunit two-part tariff allows it to reduce those rents. The solution to the problem stated (5) is therefore $r^{*}=c$, provided that Assumption 1 is satisfied. Thus, the fixed part of the contract amounts to $f=\left(\frac{a-2 c}{4}\right)^{2}-\left(\frac{a-3 c}{4}\right)^{2}$, which leads the leader/licensor's payoff to be:

$$
\pi_{L}^{u}=\left(\frac{a-2 c}{4}\right)^{2}-\left(\frac{a-3 c}{4}\right)^{2}+\frac{a^{2}+4 c(a-c)}{8}
$$

\footnotetext{
9 This is guaranteed by Assumption 1.
} 
Assume now that the licence consists of an ad-valorem two-part tariff, i.e., a fixed payment $f$ plus an ad-valorem royalty $d, 0<d<1$, proportional to the follower/ licensee's sales. In this case, the licensee chooses to produce the quantity:

$$
q_{F}=\operatorname{argmax}_{q} \pi_{F}^{v}=(1-d)\left(a-q_{L}-q\right) q
$$

where superscript $v$ denotes ad-valorem royalty regime. The solution to the problem stated in (7) leads to $q_{F}\left(q_{L}\right)=\left(a-q_{L}\right) / 2$. In turn, the leader/licensor chooses the output level:

$$
q_{L}=\operatorname{argmax}_{q} \pi_{L}^{v}=\left(a-q-q_{F}(q)\right) q+d\left(a-q-q_{F}(q)\right) q_{F}(q)
$$

which yields quantities $q_{L}=a(1-d) /(2-d)$ and $q_{F}=a /(2(2-d))$ for the licensor and licensee, respectively. Thus, the follower/licensee's profit amounts to $\pi_{F}^{v}(d)=(1-d) \frac{a^{2}}{4(2-d)^{2}}$.

On the other hand, the leader/licensor's payoff is made up of the fixed payment, $f=\pi_{F}^{v}(d)-\pi_{F}^{n}=\frac{(1-d) a^{2}}{4(2-d)^{2}}-\left(\frac{a-3 c}{4}\right)^{2}$, the royalty income, $\frac{d a^{2}}{4(2-d)^{2}}$, and the profit $\frac{(1-d) a^{2}}{2(2-d)^{2}}$ from its own production. $\pi_{L}^{v}(d)=\frac{(1-d) a^{2}}{4(2-d)^{2}}-\left(\frac{a-3 c}{4}\right)^{2}+\frac{d a^{2}}{4(2-d)^{2}}+\frac{a^{2}(1-d)}{2(2-d)^{2}}=\frac{a^{2}(3-2 d)}{4(2-d)^{2}}-\left(\frac{a-3 c}{4}\right)^{2}$ and, as result, the chosen ad-valorem royalty is that which solves:

$$
\max _{d}\left\{\frac{a^{2}(3-2 d)}{4(2-d)^{2}}-\left(\frac{a-3 c}{4}\right)^{2}\right\}, \quad \text { s.t }: \pi_{F}^{v}(d) \geq \pi_{F}^{n}
$$

Since the leader's payoff given in (9) increases and the follower's profit decreases with ad-valorem royalty $d$, ending up being zero at $d=1$, it follows that the optimal contract for the leader/licensor has no fixed payment $f$ and features an ad-valorem royalty that fulfils the follower's participation constraint, i.e. where the profit if the licence is accepted, $\pi_{F}^{v}(d)=\frac{(1-d) a^{2}}{4(2-d)^{2}}$, equals that achieved if the licence is rejected, $\pi_{F}^{n}=\frac{(a-3 c)^{2}}{16}$. Thus, the optimal ad-valorem royalty rate amounts to:

$$
d^{*}=2(\sqrt{s(1+s)}-s), \quad \text { with } s \equiv\left(\frac{a}{a-3 c}\right)^{2}-1
$$

being $0<d^{*}<1$, and, finally, the licensor's profit is:

$$
\pi_{L}^{v}=\frac{a^{2}+a \sqrt{3 c(2 a-3 c)}}{8}
$$

which, once compared with the profit given in Eq. (6), yields the following result.

Proposition 1 If the licensor plays as the leader in setting the output level, then a pure ad-valorem royalty is the preferred licensing deal.

Proof. According to Eqs. (6) and (11), the difference in the leader/licensor's profit using ad-valorem royalty or per-unit two-part tariff is 
$\pi_{L}^{v}-\pi_{L}^{u}=\frac{a \sqrt{3 c(2 a-3 c)}}{8}-\left(\left(\frac{a-2 c}{4}\right)^{2}-\left(\frac{a-3 c}{4}\right)^{2}+\frac{a^{2}+4 c(a-c)}{8}\right)$. This difference is strictly positive for $c>0$, whenever $12 a^{2}(2 a-3 c)-c(10 a-13 c)^{2}>0$ holds. Since this expression is decreasing in $c \in(0, a / 3)$, and achieves a strictly positive value at $c=a / 3$, it follows that $\pi_{L}^{v}-\pi_{L}^{u}>0$ in all the range of admissible values of parameter $c$.

Both per-unit and ad-valorem royalties modify the profit for the licensor, adding the royalty revenue to the profit from its own production. The internalization of royalty revenues implies that the leader/licensor becomes less aggressive in the product market, while the follower/licensee increases production (because of the reduction in the leader's production and also, in the case of ad-valorem royalty, because it becomes a more efficient firm). Since any increase in the follower's profit can be captured by the licensor through the fixed-fee payment, the licensor prefers the royalty that increases the industry's profits most. Both kind of royalties have a collusive effect, since total production decreases from $Q^{n}=\frac{3 a-c}{4}$ to $Q^{u}=\frac{3 a-2 c}{4}, Q^{u}<Q^{n}$, when a per-unit royalty is used, and to $Q^{v}=\frac{3 a-2 d^{*}}{2\left(2-d^{*}\right)}, Q^{v}<\stackrel{4}{Q}^{n}$, in the case of an ad-valorem royalty. Therefore, the result in Proposition 1 can be restated by stating that ad-valorem royalty is a more collusive device since total production becomes even lower than under per-unit royalty, $Q^{v}<Q^{u}$. This result extends the findings of San Martín and Saracho (2010) to a Stackelberg setting in which the licensor plays as the leader in the markeplace.

\subsection{The licensor plays as follower in setting the output level}

Assume now that the licensor chooses the quantity to produce after observing the rival's pre-committed quantity; hence the licensor is a follower in the Stackelberg game. Under per-unit two-part licensing, the follower/licensor chooses to produce the quantity given by:

$$
q_{F}=\operatorname{argmax}_{q} \pi_{F}^{u}=\left(a-q_{L}-q\right) q+r q_{L}
$$

where superscript $u$ stands (as in Sect. 3.1) for per-unit royalty. Solving the problem stated in (12) affords $q_{F}\left(q_{L}\right)=\left(a-q_{L}\right) / 2$. Note that licensing through per-unit royalty does not change the strategic interaction between leader and follower; it merely affects market outcomes if the royalty is set below the marginal cost with the old technology (and the leader/licensee has therefore lower marginal costs than in the absence of a license contract). The licensee then chooses to produce:

$$
q_{L}=\operatorname{argmax}_{q} \pi_{L}^{u}=\left(a-r-q_{F}(q)-q\right) q
$$

which yields $q_{L}=(a-2 r) / 2$ and, consequently, $q_{F}=(a+2 r) / 4$. As a result, the follower/licensor solves: 


$$
\begin{aligned}
\max _{(f, r)} \pi_{F}^{u} & =\left(f+r \frac{a-2 r}{2}\right)+\frac{(a+2 r)^{2}}{16} \\
\text { s.t } & :\left\{\begin{array}{c}
\pi_{L}^{u}(r)-f \geq \pi_{L}^{n} \\
r \leq c
\end{array}\right\}
\end{aligned}
$$

If we saturate the leader/licensee's participation constraint, then $f=\pi_{L}^{u}(r)-\pi_{L}^{n}=\frac{(a-2 r)^{2}}{8}-\frac{(a-2 c)^{2}}{8}$ and the problem stated in (14) becomes:

$$
\max _{r} \pi_{F}^{u}(r)=\frac{(a-2 r)^{2}}{8}-\frac{(a-2 c)^{2}}{8}+r \frac{a-2 r}{2}+\frac{(a+2 r)^{2}}{16}, \quad \text { s.t }: r \leq c
$$

which yields $r=c$ (provided that parameter $c$ satisfies Assumption 1). Now the follower/licensor does not want a more efficient leader/licensee, because its market share would be reduced, and the decrease in its own profit in the product market is not compensated for by the increased royalty revenue. As a consequence, per-unit royalties do not reduce competition in the product market. ${ }^{10}$ With equilibrium perunit royalty at $r=c$, production levels (and market shares) remain unchanged and the leader in the marketplace obtains the same profit as without a licence. Hence, it holds that $f=0$ when the licensor is the market follower, and the licence is then reduced to a pure per-unit royalty deal, unlike what happens when the licensor plays as the market leader. The licensee is left indifferent between accepting or refusing the licence and the licensor's profit amounts to:

$$
\pi_{L}^{u}=\frac{a^{2}+12 c(a-c)}{16}
$$

which is strictly larger than the profit without licensing, because, while the licensor's own market profit does not change, additional royalty revenue of $\frac{c(a-2 c)}{2}$ is reaped.

If, on the other hand, the follower/licensor transfers the innovation through a twopart contract featuring ad-valorem royalty $d$, it chooses to produce:

$$
q_{F}=\operatorname{argmax}_{q} \pi_{F}^{v}=\left(a-q_{L}-q\right) q+d\left(a-q_{L}-q\right) q
$$

that is, $q_{F}\left(q_{L}\right)=\left(a-(1+d) q_{L}\right) / 2$. In the presence of ad-valorem royalty the follower/licensor reduces production since the effect of a higher market price on royalty revenue is internalized. In turn, the leader/licensee chooses the quantity:

$$
q_{L}=\operatorname{argmax}_{q}=\pi_{L}^{v}=(1-d)\left(a-q_{F}\left(q_{L}\right)-q\right) q
$$

which yields $q_{L}=a /(2(1-d))$, a larger production than without the royalty because the licensee knows that the licensor will reduce its production when compared to a Stackelberg game without a license, from $\left(a-q_{L}\right) / 2$ to $\left(a-(1+d) q_{L}\right) / 2$. Thus, $q_{F}\left(q_{L}\right)=a(1-3 d) /(4(1-d))$, which is positive only if $d<1 / 3$, and, as a result, the licensor's profit amounts to $\pi_{L}^{v}(d)=\frac{(1-d) a^{2}}{8(1-d)}=\frac{a^{2}}{8}$. The licensor can then charge a

\footnotetext{
${ }^{10}$ Note that the follower/licensor ends up with a larger market share than the leader/licensee when parameter $c$ is such that $a / 6<r=c<a / 3$, i.e., when there is a noticeable improvement in technology.
} 
fixed fee equal to the increased profit of the licensee, $f=\frac{a^{2}}{8}-\frac{(a-2 c)^{2}}{8}$, and its payoff, i.e. the fixed payment plus royalty revenue and its own market profit, amounts to:

$$
\pi_{F}^{v}(d)=\left(\frac{a^{2}}{8}-\frac{(a-2 c)^{2}}{8}\right)+\frac{d a^{2}}{8(1-d)}+\frac{a^{2}(1-3 d)}{16(1-d)}=\frac{c(a-c)}{2}+\frac{a^{2}}{16}
$$

Any ad-valorem royalty $d \in(0,1 / 3]$ leads the follower/licensor to obtain the same payoff, although different royalty rates in this interval lead to different distributions between its own market profit (internal profit) and licensing revenue. An advalorem royalty substantially reduces its internal profit from $\frac{(a+2 c)^{2}}{16}$ to $\frac{a^{2}(1-3 d)}{16(1-d)}$. This is because the leader/licensee becomes much more efficient (its marginal cost goes from $c$ to zero), which leads to a direct increase in its production, and also because the licensor cuts its production for two reasons: the Stackelberg effect of an increase in the licensee's production, and internalization by the licensor that licensing revenue is enhanced by an increased final price. In any case, the licensing revenue $\left(\frac{a^{2}}{8}-\frac{(a-2 c)^{2}}{8}\right)+d \frac{a^{2}}{8(1-d)}$ more than compensates for the reduction in its internal profit.

Summing up, the follower/licensor prefers per-unit royalty to ad-valorem royalty to license its innovation, which is recorded in the following proposition.

Proposition 2 If the licensor plays as the follower in setting the output level, then pure per-unit royalty is the preferred licensing deal.

Proposition 2 shows that, when the licensor is the follower in the marketplace, an ad-valorem royalty is not an anticompetitive device, but procompetitive. The advalorem royalty is counterproductive from the licensor's point of view because it leads to a very competitive leader/licensee. Therefore, the follower/licensor settles for a per-unit royalty that leaves the market performance intact and allows profit to increase through royalty revenues.

Propositions 1 and 2 show that whether the per-unit or the ad-valorem royalty is more anticompetitive depends on whether the licensor is the leader or follower in the final market. These results depend crucially on two assumptions that we maintain throughout the paper. First, the licensor has all the bargaining power when establishing the terms of the licensing contract, whereby the licensee always obtains its outside option; thus, the licensor will choose the licensing contract that maximizes aggregate profit. Second, the contract can feature a fixed fee that allows the licensor to appropriate all the extra industry profit achieved through the agreement. Therefore, the licensor will choose the contract that maximizes industry profit (subject to the restriction that the rival cannot be shut down). 


\section{Welfare}

Once examined the impact of the licensor's market status (leader or follower in the Stackelberg game) on the kind of licensing arrangement, we now investigate the welfare consequences of licensing. To this end, we define aggregate welfare as the non-weighted sum of consumer surplus and firms' profits, i.e.

$$
W=\frac{1}{2} Q^{2}+\pi_{L}+\pi_{F}, \quad \text { where } Q=q_{L}+q_{F}
$$

and the following result emerges.

\section{Proposition 3 As compared to a no-licensing setting:}

(i) The diffusion of an innovation hurts consumers and society as a whole if the licensor is the leader in the marketplace.

(ii) The diffusion of an innovation is innocuous for consumers and benefits society as a whole if the licensor is the follower in the marketplace.

Proof (i) It is immediate that consumer surplus decreases when the licensor is the leader in the marketplace because total production decreases from $Q^{n}=\frac{3 a-c}{4}$ to $Q^{v}=\frac{3 a-2 d^{*}}{2\left(2-d^{*}\right)}, Q^{v}<Q^{n}$. Utility also decreases, since it is an increasing function of consumption in the relevant range. We must therefore check that this is not compensated for by increased production efficiency when the follower/licensee uses the new technology. With no licensing, consumer surplus amounts to $C S^{n}=(3 a-c)^{2} / 32$, industry profits to $\pi^{n}=\left(3 a^{2}-2 a c+11 c^{2}\right) / 16$, and, consequently, aggregate welfare to $W^{n}=\left(15 a^{2}-10 a c+23 c^{2}\right) / 32$. In contrast, with licensing by means of pure ad-valorem royalty contract according to Proposition 1 , consumer surplus amounts to $C S^{\nu}=a^{2}(3-2 d)^{2} / 8(2-d)^{2}$, and industry profits to $\pi^{v}=a^{2}(3-2 d) / 4(2-d)^{2}$, whereby total welfare is $W^{v}=a^{2}(3-2 d)(5-2 d) / 8(2-d)^{2}$. Comparison of $W^{n}$ with $W^{v}$ yields the stated result in part (i).

(ii) The fact that industry output is constant in $d$ implies that consumer surplus is not affected when the follower in the marketplace licenses its technology to the leader (through a contract that features ad-valorem royalty). Aggregate welfare, on the other hand, improves with licensing because the leader/licensee produces with a more efficient technology; this translates into higher profit for the follower/licensor through licensing revenues.

As compared to the no-licensing setting, the diffusion of an innovation is innocuous for consumers when the licensor is the follower in the marketplace, but hurts consumers otherwise. Licensing an innovation in the hands of the market leader is a collusive device, and consumers end up paying a higher price than if licensing did not occur. An innovation in the hands of a follower in the product market, in contrast, leaves consumers unaffected and licensing is only a way to increase production efficiency (and industry profits as a consequence). We can thus argue than a new technology in the 
hands of a follower in the marketplace and licensed to a leader in that market has more social value than if its holder were a leader that licenses to a follower.

\section{Incentives to innovate}

What sort of firm - a leading firm or a following firm in the product market-has a greater incentive to obtain the new technology? To evaluate the incentive of a firm to innovate we use as an indicator the increased profit of the firm that already got the new technology and decides to license it to a rival. Although for most of the admissible values of parameter $c$ that measures the size of the innovation, it is the market leader who has the most incentives to innovate, there are, however, admissible values of $c$ for which it is the market follower who has the most incentives. This is recorded in the following proposition.

Proposition 4 There is a cut-off value for the size of the innovation, $c^{*} \approx 0.292 \cdot a$, being $0<c^{*}<a / 3$, such that the following hold:

(i) A leader in setting the output level has greater incentive to develop an innovation of size $c<c^{*}$ than a follower in setting the output level.

(ii) A follower in setting the output level has greater incentive to develop an innovation of size $c>c^{*}$ than a leader in setting the output level.

Proof For an innovator that plays as a leader in the product market and engages in R\&D to obtain the new technology the increase in its profit as compared to the situation in which it does not innovate amounts to:

$$
\frac{a^{2}+a \sqrt{3 c(2 a-3 c)}}{8}-\frac{(a-c)^{2}}{8}=\frac{a \sqrt{3 c(2 a-3 c)}+c(2 a-c)}{8}
$$

On the other hand, for an innovator that plays as a follower in the product market and has the new technology the increase in its profit as compared to the situation in which it does not innovate is:

$$
\frac{a^{2}+12 c(a-c)}{16}-\frac{(a-c)^{2}}{16}=\frac{12 c(a-2 c)+c(2 a-c)}{16}
$$

The value $c^{*}$ stated in Proposition 4 is the solution in the interval $(0, a / 3)$ of equalling Eqs. (21) and (22), or the solution of the third-degree equation in $c$ given by $12(2 a-3 c)-c(10 a-11 c)^{2}=0$. Finally, the two statements in the proposition are the result of comparing Eqs. (21) and (22) above and below cut-off value $c^{*}$.

There are three channels through which an innovation creates value for an innovator/licensor that plays as a leader in the product market. The first one is the direct leadership effect in the Stackelberg model: the leader is a much larger firm than the follower in terms of market share, and the increased efficiency induced by the new technology implies a much greater impact on the leader's profit. This channel only 
loses its relevance when the value of parameter $c$ is very large, i.e. when the old technology is very inefficient, since the innovative firm would become a monopoly.

When the value of parameter $c$ is very large, two other channels, both related with the incentives to disseminate the innovation through a licensing deal, become relevant to create value for the innovator/licensor. First, licensing increases the production efficiency of the licensee, and the licensor reaps royalty revenues in exchange for facilitating this improvement. This channel is less relevant when the licensor is the market leader than when it is the market follower, because it is already the firm with the greatest market share, and also when the marginal cost $c$ is low, i.e. when the old technology is almost as efficient as the new one. Second, licensing an innovation creates value for the innovator/licensor when the licence acts as a collusive device. According to Proposition 2, this channel is not present when the innovator/licensor is the follower in the product market. As a result, for sufficiently high values of marginal cost $c$, it is important for industry profit if the market leader moves from the old to the new technology; hence, in this case it is the follower in setting the output level that has more incentives to innovate.

\section{Final remarks}

We have demonstrated that when an inside licensor licenses a cost-reducing innovation, its position in the product market plays a crucial role in the choice of per-unit or ad-valorem royalty for the licensing deal. This is because the effect of each kind of royalties on industry performance depends on whether the licensor is the leader or the follower in setting the output level. In other words, we have shown that we cannot claim that a per-unit royalty is a more anticompetitive device than an advalorem royalty, or the other way around, because, in fact, their effects will depend on the details of the industry.

One important aspect of the set-up developed in this paper is that we can easily evaluate the licensing impact on aggregate welfare. Since licensing tends to create a more collusive product market, in welfare terms the increase in productive efficiency never compensates for the reduction in consumer surplus. As a consequence, only licensing that is innocuous for consumers can lead to welfare improvement.

Regarding the incentives to engage in $R \& D$ activities that lead to a new technology we showed that they largely depend on the size of the innovation achieved and the market status of the innovator/licensor. Obviating any restriction to performing $\mathrm{R} \& \mathrm{D}$, our model suggests that a firm playing as a leader (follower) in the product market is more incentivized to undertake and to license a small (large) innovation than a firm that plays as a follower (leader). In a sense, this could be understood as a form of decreasing relationship between a firm's size and its innovative activity.

There are two extensions of the model handled in this article that would be worth exploring. First, we considered in our research the case of homogenous goods, so it would be useful to extend the Stackelberg framework to a set-up with differentiated products. In a product variety situation, we suspect that the anticompetitive impact 
of licensing would be reduced; if this were the case, then the increase in production efficiency from licensing could translate into improved consumer surplus.

Second, we used the Stackelberg model as a reduced form to represent that a firm (the leader) has a competitive advantage over a rival (the follower). For a more detailed discussion of any particular industry, it would be useful to build a leader/ follower model with micro-foundations based on the technological and institutional details of the industry under study (e.g., the leader is a platform in an industry with network effects) and then to analyse the role of both kind of royalties (per-unit royalty and ad-valorem royalty) for that particular industry. The analysis of these extensions is left for future research.

Acknowledgements The authors wish to thank the Editor and two anonymous referees for their useful comments and suggestions.

Funding Open Access funding provided thanks to the CRUE-CSIC agreement with Springer Nature. Manel Antelo acknowledges financial support from Consellería de Cultura, Educación e Ordenación Universitaria (Xunta de Galicia) through Grant GRC 2019 and Lluis Bru from the Ministerio de Economía e Innovación (Gobierno de España) (ECO2017) through Grant PID2020-115018RB-C33. Beyond this, the paper received no specific grant from any funding agency in the public, commercial, or non-profit sectors.

\section{Declarations}

Conflict of interest The authors declare that they have no conflict of interest regarding this research.

Availability of data and material (data transparency) Not applicable.

Code availability (software application or custom code) Not applicable.

Open Access This article is licensed under a Creative Commons Attribution 4.0 International License, which permits use, sharing, adaptation, distribution and reproduction in any medium or format, as long as you give appropriate credit to the original author(s) and the source, provide a link to the Creative Commons licence, and indicate if changes were made. The images or other third party material in this article are included in the article's Creative Commons licence, unless indicated otherwise in a credit line to the material. If material is not included in the article's Creative Commons licence and your intended use is not permitted by statutory regulation or exceeds the permitted use, you will need to obtain permission directly from the copyright holder. To view a copy of this licence, visit http://creativecommons.org/licen ses/by/4.0/.

\section{References}

Acs, Z. J., \& Audretsch, D. B. (1987). Innovation and firm size in manufacturing. Technovation, 7, 197-210.

Acs, Z. J., \& Audretsch, D. B. (1990). Innovation and small firms. MIT Press.

Bousquet, A., Cremer, H., Ivaldi, M., \& Wolkowicz, M. (1998). Risk sharing in licensing. International Journal of Industrial Organization, 16, 535-554.

Czarnitzki, D., \& Kraft, K. (2004). An empirical test of the asymmetric models on innovative activity: Who invests more into R\&D, the incumbent or the challenger? Journal of Economic Behavior and Organization, 54, 153-173.

Fan, C., Jun, B. H., \& Wolfstetter, E. G. (2018a). Per unit vs. ad valorem royalty licensing. Economics Letters, $170,71-75$. 
Fan, C., Jun, B. H., \& Wolfstetter, E. G. (2018b). Optimal licensing under incomplete information: The case of the inside patent holder. Economic Theory, 66, 979-1005.

Filippini, L. (2005). Licensing contract in a Stackelberg model. Manchester School, 73, 582-598.

Huergo, E., \& Jaumandreu, J. (2004). How does probability of innovation change with firm age? Small Business Economics, 22, 193-207.

Jiang, B., \& Shi, H. (2018). Inter-competitor licensing and product innovation. Journal of Marketing Research, 55, 738-751.

Kabiraj, T. (2005). Technology transfer in a Stackelberg structure: Licensing contracts and welfare. Manchester School, 73, 1-28.

Lim, T., \& Veugelers, R. (2003). On equity as a payment device in technology licensing with moral hazard. Leuven: Working paper Katholieke Universiteit Leuven.

Radauer, A., \& Dudenbostel, T. (2013). Patlice survey: Survey on patent licensing activities by patenting firms. Leuven: European Commission.

Reinganum, J. (1983). Uncertain innovation and persistence of monopoly. American Economic Review, 73, 741-748.

San Martín, M., \& Saracho, A. I. (2010). Royalty licensing. Economics Letters, 107, 284-287.

San Martín, M., \& Saracho, A. I. (2016). Patent strenght and optimal two-part tariff licensing with a potential rival incorporating ad valorem royalties. Economics Letters, 143, 28-31.

Trombini, G., \& A. Comacchio (2012), Corporate markets for ideas: when does technology licensing combine with R\&D partnerships? Working Paper 8, Department of Management, Università Ca'Foscari Venezia.

Wang, H., \& Yang, B. Z. (2004). On technology licensing in a Stackelberg duopoly. Australian Economic Papers, 43, 448-458.

Zuniga, P., \& Guellec, D. (2009). Who licenses out patents and why? Lessons for a business strategy. STI Working Paper No. 2009/5.

Publisher's Note Springer Nature remains neutral with regard to jurisdictional claims in published maps and institutional affiliations. 